\title{
Can Nutritional Supports Beneficial in Other Viral Diseases Be Favorable for COVID-19?
}

\author{
Fatmanur Zehra Zelka', Rümeysa Rabia Kocatürk', Öznur Özge Özcan², Mesut Karahan²,* \\ ${ }^{1}$ Faculty of Health Sciences, Üsküdar University, Istanbul, Turkey \\ ${ }^{2}$ Vocational School of Health Services, Üsküdar University, Istanbul, Turkey
}

The coronavirus disease 2019 (COVID-19) pandemic, caused by severe acute respiratory syndrome coronavirus-2 (SARS-COV-2), has rapidly spread worldwide, causing many deaths, the number of which continues to increase. Global public health organizations and governments have advised on the adoption of various handwashing and hygiene guidelines, use of masks, and social distancing, along with isolation or lockdown protocols to prevent SARS-COV-2 spread. There are vaccines and drugs that are confirmed but still many human suffer from this disease. Important risk factors for SARS-COV-2 infection are similar to other viral infectious diseases as including influenza, hepatitis B, acquired immunodeficiency syndrome, and other lung infections. These diseases might be related to poor nutritional support, affecting the patient outcomes against COVID-19. In this review, we discuss some of the nutritional therapies currently being investigated for infectious diseases. Studies have shown that nutrition has the potential to prevent and mitigate viral infections. Micronutrients (vitamins A, B6, B12, C, D, and E, B9, and trace elements, such as iron, zinc, copper, selenium, magnesium, and polyphenols) and macronutrients (carbohydrates, prebiotics, probiotics, protein [amino acids], and lipids [fatty acids]) affect the whole body, including the immune system, preventing viral entry and modulating clinical symptoms. This review discusses the importance of nutrition as a strategy to understand food groups and key nutrients that may affect the clinical outcomes of COVID-19 patients during the ongoing pandemic. Scientists believe that the likelihood of another pandemic is imminent. COVID-19 remains important and scientists believe it will continue will in the future. We emphasize the lack of studies on the nutritional impact of COVID-19 in terms of nutrition, even though nutritional interventions has been shown to have many advantages during the treatment of viral infections.

Keywords: Disease Management; Immunity; Nutrition Therapy; Viral Infection; Prevention and Control; SARSCOV-2 


\section{INTRODUCTION}

The new type of coronavirus known as severe acute respiratory syndrome coronavirus-2 (SARS-COV-2) was first detected in Wuhan (Hubei province), China, in 2019. ${ }^{1)}$ SARS-COV-2 became a global human threat and the infection caused by it, coronavirus disease 2019 (COVID-19), was declared a pandemic, ${ }^{2)}$ with 5,51 million total confirmed deaths by January $12,2022 .{ }^{3)}$ The emergence and rapid spread of new variants of SARS-COV-2 have further increased the global health threat in recent months. ${ }^{4)}$ COVID-19 symptoms range from mild to severe symptoms that can lead to death. Symptoms including cough, fever, pneumonia, and shortness of breath usually appear for 2-14 days after viral exposure and infection. The infected individuals may also show hepatic, respiratory, neurological, and gastrointestinal complications that can eventually lead to death..$^{5-8)}$ Elderly patients and those who required intensive care support mostly had multiple comorbidities, including cardiovascular, cerebrovascular, endocrine, digestive, and respiratory diseases. ${ }^{5,9)}$ Though young and healthy people do not fall under major risk groups, they could act as carriers affecting the higherrisk groups. ${ }^{5,10,11)}$ Therefore, standard public health practices have been advised to help decrease exposure and avoid spreading these respiratory viruses. ${ }^{11-13)}$ Immunization with a vaccine that stimulates the immune system is the best way to avoid contracting COVID-19, prevent infection, and reduce mortality. Unfortunately, although there are approved vaccine agents and drug studies, SARS-COV-2 has not prevented its progression. ${ }^{14-16)}$

To support the immune system and avoid the adverse effects of viral infection, additional strategies need to be identified; in this respect, nutrition can be supportive. ${ }^{17)}$ Substantial evidence highlights the effects of diet on the immune system and combating illnesses. It has been shown that particular nutrient supplements can affect the immune system through molecular signaling modifications, gene expression, cell activation, and gut microbial composition determinants. ${ }^{18,19)}$
Nutritional insufficiencies in terms of energy intake, protein intake, and specific micronutrient intake are associated with a suppressed immune system function and are highly associated with increased sensitivity to infection. The continuity of the immune system functions is highly dependent on the adequate intake of micronutrients such as zinc ( $\mathrm{Zn})$, iron (Fe), copper (Cu), selenium (Se), magnesium (Mg), and vitamins $\mathrm{A}, \mathrm{B} 6, \mathrm{~B} 12$, and $\mathrm{E}^{20,21)}$

To date, there are studies available on the effect of nutrition, disease symptoms and immune system and viral entry on COVID-19 patients. ${ }^{22)}$ However, in the context of other viral diseases that have been examined, nutrition may be a key factor that may affect the outcomes of COVID-19. International commissions, especially in China, advise that sufficient energy intake from foods and vitamins can improve disease outcomes. ${ }^{23)}$ This review discusses the importance of nutrition (consuming adequate amounts of sufficient nutrients: macronutrients [protein, carbohydrates, lipids] and micronutrients [vitamins, minerals]) to strengthen the immune system, decrease intensive care unit (ICU) and hospitalization time, and lower the mortality rate and mechanical ventilation (MV) time. Better nutritional quality can improve the experience of individual patients as well as the general public during the COVID-19 pandemic.

\section{IMMUNOLOGY OF COVID-19}

SARS-COV-2 infection generally activates both innate and adaptive immune cells, as shown in Figure $1{ }^{24)}$ However, the innate and adaptive immune responses trigger uncontrolled inflammatory responses both locally and systemically, leading to tissue damage. In patients with severe SARS-COV-2, lymphopenia (low lymphocyte count) is common and is associated with a decrease in innate and adaptive immune response. For example, the decrease in the number of immune cells, such as the percentage of monocytes, basophils, eosinophils, CD4+ T cells, CD8+ T cells, B cells, and natural killer (NK) cells, is a

\section{Immune system}

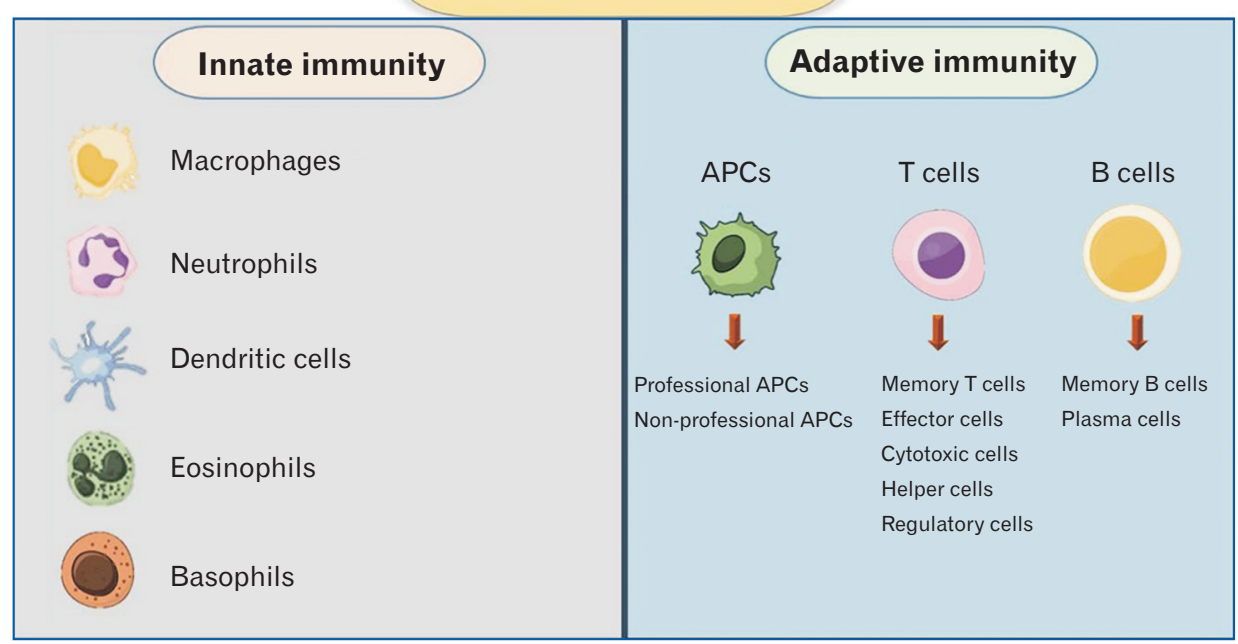

Figure 1. Immune cells. Types and characteristics of immune cells in the innate and adaptive immune systems. ${ }^{24)}$ APCs, antigenpresenting cells. 
symptom of lymphopenia, which is directly proportional to the severity of the existing infection. ${ }^{25-30)}$ Lymphopenia is also observed in conjunction with an increase in neutrophil count and neutrophil-lymphocyte ratio, higher disease severity, and poor prognosis. ${ }^{29)}$

Receptor CD94/NK group 2 member A is noteworthy in COVID-19like patients. This receptor is known to cause a decrease in NK and CD8+ T cell counts. Additionally, peripheral CD4+ and CD8+ T cells decreased, and hyperactivation was observed in COVID-19 patients. In these patients, complex cells such as CD3+ T and CD4+ T, as well as cytotoxic granules in CD8 + T cells, were also identified. The presence of these cells is an indication of excessive $\mathrm{T}$ cell activation and antiviral immune response. ${ }^{26,31-33)}$ In clinical studies on COVID-19 patients, analysis of blood serum found increased immunoglobulin $\mathrm{G}$ response and a higher total antibody titer relative to healthy controls. However, these results were associated with poor prognosis in patients. ${ }^{29,34)} \mathrm{CO}-$ VID-19 can cause multiple disorders, one of which is acute respiratory distress syndrome (ARDS). The primary mechanism for ARDS is the increase in inflammatory cytokines, leading to fatal responses in patients. For this reason, these pro-inflammatory cytokines (such as interferon-alpha [IFN- $\alpha$ ], IFN- $\gamma$, interleukin [IL]-1 $\beta$, IL-6, IL-12, IL-18, IL33 , tumor necrosis factor [TNF- $\alpha$ ], transforming growth factor- $\beta$ [TGF- $\beta$ ]) and chemokines (such as CC chemokine ligand 2 [CCL2], CCL3, CCL5, CXC motif chemokine receptor 8 [CXCL8], CXCL9,
CXCL10) should be examined and, if possible, kept under control to protect against ARDS. ${ }^{25,35-37)}$ Patients with severe COVID-19 present with high levels of IL-6, IFN- $\alpha$, CCL5, CXCL8, and CXCL10 in the serum compared to those with mild or moderate disease. Severe symptoms are also associated with high IL-6 levels and IL-1 $\beta$, in addition to pro-inflammatory levels of IL-2, IL-8, IL-17, granulocyte-colony stimulating factor, granulocyte macrophage-colony-stimulating factor, interferon-bound protein 10, monocyte chemoattractant protein-1 (MCP1), macrophage inflammatory protein 1 a (also known as CCL3); TNF levels were also found to be significantly high in the clinical studies. ${ }^{25-28,38)}$ Most of the symptoms caused by SARS-COV-2 were similar to the infection in severe acute respiratory syndrome coronavirus (SARS-COV) and Middle East respiratory syndrome (MERS-COV) infection. The increase in cytokine levels in these three different viruses causes a cytokine storm on the body by the immune system. As a result, response to the infection causes ARDS and multiple organ failure $^{26)}$ Coronavirus infections also demonstrate high amounts of C-reactive protein and D-dimers in the serum. The high rate of pro-inflammatory cytokines can lead to septic shock, heart, liver, and kidney tissue damage and respiratory failure in patients. Cytokine storm can also lead to a large infiltration of neutrophils and macrophages, mediating extensive pulmonary pathology with the formation of hyaline membranes, widespread alveolar wall thickening, and alveolar dam-

Table 1. Effects macronutrients on the innate and adaptive immune system

\begin{tabular}{|c|c|c|c|}
\hline Macronutrient & Innate immune system & Adaptive immune system & References \\
\hline $\begin{array}{l}\text { High saturated fatty } \\
\text { acids }\end{array}$ & $\begin{array}{l}\text { Highly saturated fatty acids are the building blocks of lipids. It } \\
\text { leads to chronic activation of the innate immune system, can } \\
\text { activate the innate immune system through the activation of } \\
\text { TLRs (e.g., TLR4) expressed on neutrophils and induce a } \\
\text { lipotoxic condition. It provides stimulation of macrophages, } \\
\text { dendritic cells, and canonical inflammatory signaling pathways } \\
\text { that produce pro-inflammatory mediators and other effectors } \\
\text { of the innate immune system in the body. }\end{array}$ & $\begin{array}{l}\text { Highly saturated fatty acids induce oxidative stress. It impairs } \\
\text { the proliferation and maturation of T and B cells. In } \\
\text { particular, it prevents the B cell from functioning, causing } \\
\text { apoptosis of the lymphocyte. It is generally responsible for } \\
\text { the suppression of the adaptive immune system. }\end{array}$ & $44,45)$ \\
\hline PUFA, n-3-PUFA & $\begin{array}{l}\text { PUFAs are another composition that forms lipids and are } \\
\text { unsaturated fatty acids. It shows anti-inflammatory and } \\
\text { immune regulating effects. }\end{array}$ & $\begin{array}{l}\text { Long chain PUFAs, unlike high saturated fatty acids, regulate } \\
\text { adaptive immune responses and have a mediating role in } \\
\text { the formation of these responses. }\end{array}$ & $41,46)$ \\
\hline Carbohydrates & $\begin{array}{l}\text { Carbohydrates are considered the main nutrient of the body and } \\
\text { maintain blood sugar during exercise. It provides lower } \\
\text { release of stress hormones, affects the inflammation caused } \\
\text { by innate immunity after exercise and associated immune } \\
\text { changes. Energy is required for adequate immune response } \\
\text { to occur, to perform macrophages, neutrophils and their } \\
\text { immunological roles. This energy provides the formation of } \\
\text { adenosine triphosphate by using glucose in mitochondria. } \\
\text { Therefore, carbohydrates have an important role for immune } \\
\text { cells. }\end{array}$ & $\begin{array}{l}\text { Carbohydrates are energizing compounds. It has effects on } \mathrm{T} \\
\text { and } \mathrm{B} \text { lymphocytes. It has a key role for an adequate } \\
\text { adaptive immune response. }\end{array}$ & $41,47,48)$ \\
\hline Probiotics, prebiotics & $\begin{array}{l}\text { Probiotics are living microorganisms found in fermented } \\
\text { nutrients, and prebiotics are nutrients that contain substances } \\
\text { that the human body cannot digest. It improves intestinal } \\
\text { microbial flora, thereby increasing immune function and } \\
\text { response with a reduction in rates of infection. }\end{array}$ & $\begin{array}{l}\text { Probiotics and prebiotics have effects on T regulatory cells, } \\
\text { effector lymphocytes, natural killer T cells and B cells in the } \\
\text { adaptive immune system. It takes part in the regulation of } \\
\text { the adaptive immune system. }\end{array}$ & $41,49)$ \\
\hline Proteins (amino acids) & $\begin{array}{l}\text { Proteins are structures made up of amino acids. Amino acids } \\
\text { have important roles in the immune system. It supports innate } \\
\text { immune systems, including stimulation of immune cell } \\
\text { function, as in neutrophils. }\end{array}$ & $\begin{array}{l}\text { Proteins contain amino acids in their structure and these } \\
\text { amino acids have many immune system supporting roles. } \\
\text { In particular, its immunomodulatory role is remarkable. It } \\
\text { has positive effects on T cell proliferation and activation. }\end{array}$ & $43,50,51)$ \\
\hline
\end{tabular}

TLR, toll-like receptor; PUFA, polyunsaturated fatty acids. 
Table 2. Effects micronutrients on the innate and adaptive immune system

\begin{tabular}{|c|c|}
\hline Micronutrient & Innate immune system \\
\hline Vitamin A & $\begin{array}{l}\text { Vitamin A helps maintain the structural and functional integrity of } \\
\text { mucosal cells in many natural barriers such as the respiratory } \\
\text { tract. Vitamin A plays a role in the normal functioning of NK cells, }\end{array}$ \\
\hline
\end{tabular}

Vitamin B6 vitamin B12

Vitamin B6 plays a role in the activation of NK cells and also helps regulate inflammation, as well as have roles in producing inflammatory cytokines.

Vitamin B12 has a big role in regulating NK cell functions, and it also has important functions in many systems, including the nervous system.

Vitamin C Vitamin C supports the integrity of epithelial barriers with its role in collagen synthesis, stimulates production, functioning and movement of leukocytes in innate immunity. It increases the serum levels of complementary proteins such as neutrophils, lymphocytes, phagocytes. They have roles in NK cell activities and have roles in stimulate macrophages for chemotaxis, apoptosis, and removal of spent neutrophils from the sites of infection. It shows antimicrobial effect. It also acts as a protective antioxidant against ROS and RNS that occur during the immune system's destruction of pathogens.

Vitamin D Vitamin D has many effects on innate immune cells. One of them is that it increases numbers in monocytes, macrophages, dendritic cells. In addition, vitamin D may increase immune cell proliferation and differentiation of monocytes into macrophages. Vitamin D its known to regulate the synthesis of the antimicrobial proteins Cathelicidin and Defensin. These proteins have the capacity to directly kill pathogens, especially bacteria. It also stimulates cytokine production and helps protect from the infections caused by active pathogens.

Vitamin $\mathrm{E} \quad$ Vitamin $\mathrm{E}$ has an important antioxidative role in innate immunity. It increases IL-2 production and cytotoxic activities of NK cells that uses in infectious diseases, and its antioxidative properties help protect the integrity of cell membranes from damage caused by free radicals.

Polyphenols Polyphenols are a group containing many bioactive chemicals. Many diseases such as general mortality, chronic health conditions, acute respiratory disease and chronic inflammations have been alleviated in high dietary intake of polyphenols. Its contribution to innate immunity controls NK cell activities, macrophage inflammatory responses, as well as has antiviral effects.

Folate Folate plays an active role in the protection of innate immunity, especially it helps protect NK cells. Besides, folate has many positive effects on human health.
Copper
Copper is an antimicrobial and antioxidant trace element. It accumulates in the areas of inflammation and is involved in the fight against bacterial infections in the innate immune system. It is also important for IL-2 production.
Iron

In the presence of vitamin, $A$, the work of adaptive immune system cells $T$ and $B$ lymphocytes is regulated. This vitamin is necessary to produce antibody responses to the antigen. It also has an active role in many responses, from the development and differentiation of Th such as Th1 and Th2 cells. For example, supporting Th2 anti-inflammatory response

B6 has many different functions at the adaptive immune system from the endogenous synthesis and metabolism of amino acids, the building blocks of cytokines and antibodies, lymphocyte proliferation, differentiation and to maturation, and this vitamin is also helping maintain immune response with Th1 cells and plays a role in antibody production.

Vitamin B12 has the following roles in cellular and adaptive immunity: production of $\mathrm{T}$ lymphocytes, influence of $\mathrm{CD} 8+\mathrm{T}$ cells that act as immunomodulators, affecting the single carbon metabolism that the interactions with folate is involved.

Vitamin $C$ can increase the serum levels of $B$ and $T$ antibodies in the adaptive immune system and play an active role in the differentiation and proliferation of lymphocytes.

Vitamin $D$ has a fundamentally inhibitory effects on adaptive immune cells such as T and B lymphocytes. Such as inhibits antibody production by stimulating $B$ cells and also inhibits $T$ cell reproduction

Vitamin $E$ regulates the functions mediated by the $T$ lymphocyte $52,53)$ cell in the adaptive immune system, ensures lymphocyte proliferation and has effects on T helper cells. For example, it optimizes Th1 but also improves and suppresses the Th2 response.

Regulatory T (Treg) cells are cells that help restrain the immune system and prevent excessive T Cell response. Polyphenols play an active role in modulating Treg cells.

Folate has important roles in cell-mediated immunity, namely in 52,54 the adaptive immune system, for adequate antibody response to antigens and has effects on T helper cells. For example, folate supports the formation of Th1 mediated immune response.

Copper plays a role in the proliferation of $\mathrm{T}$ lymphocyte cells in the adaptive immune system. Copper plays a role in the production of antibodies to $\mathrm{B}$ lymphocytes and has an active role in cellular immunity.

Iron has many roles in adaptive immunity. It plays a role as a component of critical enzymes for the functioning of immune cells, which are essential for cell differentiation and growth, and have roles in lymphocyte differentiation and growth. It is a component of the ribonucleotide reductase enzyme, which is especially involved in DNA synthesis. It is effective in the synthesis of $\mathrm{T}$ lymphocytes.

$52,53)$

\section{References}


Table 2. Continued

\begin{tabular}{|c|c|c|c|}
\hline Micronutrient & Innate immune system & Adaptive immune system & References \\
\hline Selenium & $\begin{array}{l}\text { Selenium trace element is the building block of selenium- } \\
\text { dependent enzymes (selenoproteins) in our body. Selenoproteins } \\
\text { function as redox regulators and cellular antioxidants. It is an } \\
\text { important part of the antioxidant host defense system that affects } \\
\text { leukocytes and NK cell function. }\end{array}$ & $\begin{array}{l}\text { Selenium is an important trace element, it has roles in T } \\
\text { lymphocyte proliferation, and has roles in the humoral system, } \\
\text { such as the production of immunoglobulin. }\end{array}$ & $52,54,60)$ \\
\hline Zinc & $\begin{array}{l}\text { Zinc trace element acts as an antioxidant that protects against ROS } \\
\text { and RNS. It also helps maintain skin and mucosal membrane } \\
\text { integrity for the innate immune system. }\end{array}$ & $\begin{array}{l}\text { Zinc is important for the component of critical enzymes such as } \\
\text { ribonucleotide reductase enzyme involved in DNA synthesis for } \\
\text { the functioning of adaptive immune cells. This trace element } \\
\text { helps modulate cytokine release so it can control acute } \\
\text { respiratory distress syndrome as well as induce proliferation of } \\
\text { CD8+T cells. }\end{array}$ & $52,56,62)$ \\
\hline
\end{tabular}

NK, natural killer; Th, T helper; ROS, reactive oxygen species; RNS, reactive nitrogen species; IL-2, interleukin-2.

age, consequently leading to mortality. This event is called immunemediated damage; spleen atrophy and lymph node necrosis are associated with immune-mediated damage. ${ }^{39)}$ Several markers, such as CD4+ T cell, CD8+ T cell, B cell, NK cell, and cytotoxic lymphocyte, have been found to normalize in patients who have recovered. The number of immune cells in the patients' serum returned to normal rates. $^{33,39)}$

\section{EFFECT OF NUTRITION ON THE IMMUNE SYSTEM}

Well-balanced nutrition and hydration are vital for a stronger immune system and lowering the risk of chronic illnesses and infectious diseases. It is essential to consume adequate micro-and macronutrients that the body needs, avoid excess sugar, fat, and salt, and drink enough water to significantly lower the risk of many health problems. ${ }^{40)}$ Many nutrients are needed to sustain life, such as micronutrients (vitamins $\mathrm{A}$, B6, B12, C, D, E, and folate; trace elements such as $\mathrm{Zn}, \mathrm{Fe}, \mathrm{Se}, \mathrm{Cu}$, and $\mathrm{Mg}$; polyphenols) and macronutrients (carbohydrates, prebiotics, probiotics, protein [amino acids], and lipids [fatty acids]). These nutrients play important roles in supporting innate and adaptive immune systems (Tables 1, 2). ${ }^{21,41-62)}$ Vitamins and minerals also have significant roles in the immune system (Figure 2). ${ }^{21)}$ Foods play pleiotropic roles to augment the immune system, and immune responses are supported by food in different ways. Food contributes to physical barriers in the natural immune system: the production and activity of antimicrobial proteins that function in the body; growth, differentiation, and motility of congenital cells are of great importance; phagocytic and lethal activities of neutrophils and macrophages such as oxidative explosion; and anti-inflammatory effects such as cytokine production and antioxidant activity. Nutrients also have functions in the adaptive immune system, including T- and B-lymphocyte differentiation, proliferation, homeostasis, and controls the production of cytokines, B antibodies, and memory cells (Tables 1, 2 and Figure 1). ${ }^{17,24,41,43-62)}$ Therefore, immune function is negatively affected in the case of insufficient micronutrients and macronutrients, resulting in a potential decrease in the immunity against infections. ${ }^{21,41-43)}$

Several clinical, in vivo, and in vitro studies with different viruses have shown the benefits of the micro-and macronutrients in support- ing the immune system and making progress in the patient's recovery. In a study of influenza vaccination with oral gummy intake (vitamin A 20,000 IU and vitamin D 2,000 IU), children were found to have increased antibody response. ${ }^{63)}$ Supplementing vitamin D (6 doses $100,000 \mathrm{IU}, 1$ vial per 15-day period) with influenza vaccination led to higher TGF- $\beta$ plasma levels, indicating a tolerogenic immune response and direct lymphocyte polarization. ${ }^{64)}$ This supports the assertion that vitamins A and D augment immunization outcomes. Vitamin D3 (2,000 IU/d) intake by hepatitis C patients was highly associated with virological response. ${ }^{65,66)}$ Vitamin E (15 mg/kg/d) supplementation in children with chronic hepatitis B was associated with increased virological response than the control group (odds ratio [OR], 3.96; 95\% confidence interval [CI], 1.18-13.25; $\mathrm{P}=0.025) .{ }^{67)}$ In a study with influenza-infected Gulo (-/-) mice, serum vitamin $\mathrm{C}$ concentration dropped from $80-100 \mu \mathrm{M}$ to $10-20 \mu \mathrm{M}$, and a decrease of antiviral immune responses was observed through the decrease of IFN-IL- $1 \alpha / \beta$ production, indicating that vitamin $\mathrm{C}$ is important for its production. ${ }^{68)}$ Treatment with zinc sulfate ( $10 \mathrm{mg}$ for < 1-year-old; $20 \mathrm{mg}$ otherwise) in children with pneumonia increased levels of IFN-gamma (IFN- $\gamma$ ) and IL-2 and showed an improvement in the patients' clinical status (76 \pm 7 versus $105 \pm 8, P=0.01$ ), respiratory rate ( $37 \pm 6$ versus $57 \pm 7$, $\mathrm{P}=0.04$ ), and oxygen saturation ( $53 \pm 7$ versus $87 \pm 9, \mathrm{P}=0.007$ ) within a few hours compared to that in the placebo group. ${ }^{69)}$ To detect improvement in the immune function, healthy participants were provided with copper supplements at mealtime for 0-18 days ( $1.6 \mathrm{mg}$ per day), 19-129 days ( $7 \mathrm{mg}$ per day), and 130-148 days (7.8 mg per day); white blood cells, lymphocytes, and IL-2 receptor levels were altered $(\mathrm{P}<0.05) .{ }^{70)}$ In contrast, high amounts of refined carbohydrates, sugar, and saturated fat in the high-fat diet (HFD), along with consumption of low levels of fiber, unsaturated fats, and antioxidants, significantly impairs adaptive immunity and significantly neutralizes the defense system against viral pathogens. Therefore, providing nutrition in the form of natural and healthy foods is important to develop immunity against infectious diseases. ${ }^{71)}$ HFD-fed mice with influenza tend to have increased macrophage infiltration into the lung tissue, especially in the alveoli, contributing to poor immune responses such as adaptive immune response delay and an increase in lung pathology. In addition, in mice fed with HFD, memory T cell deficiency, impaired re- 


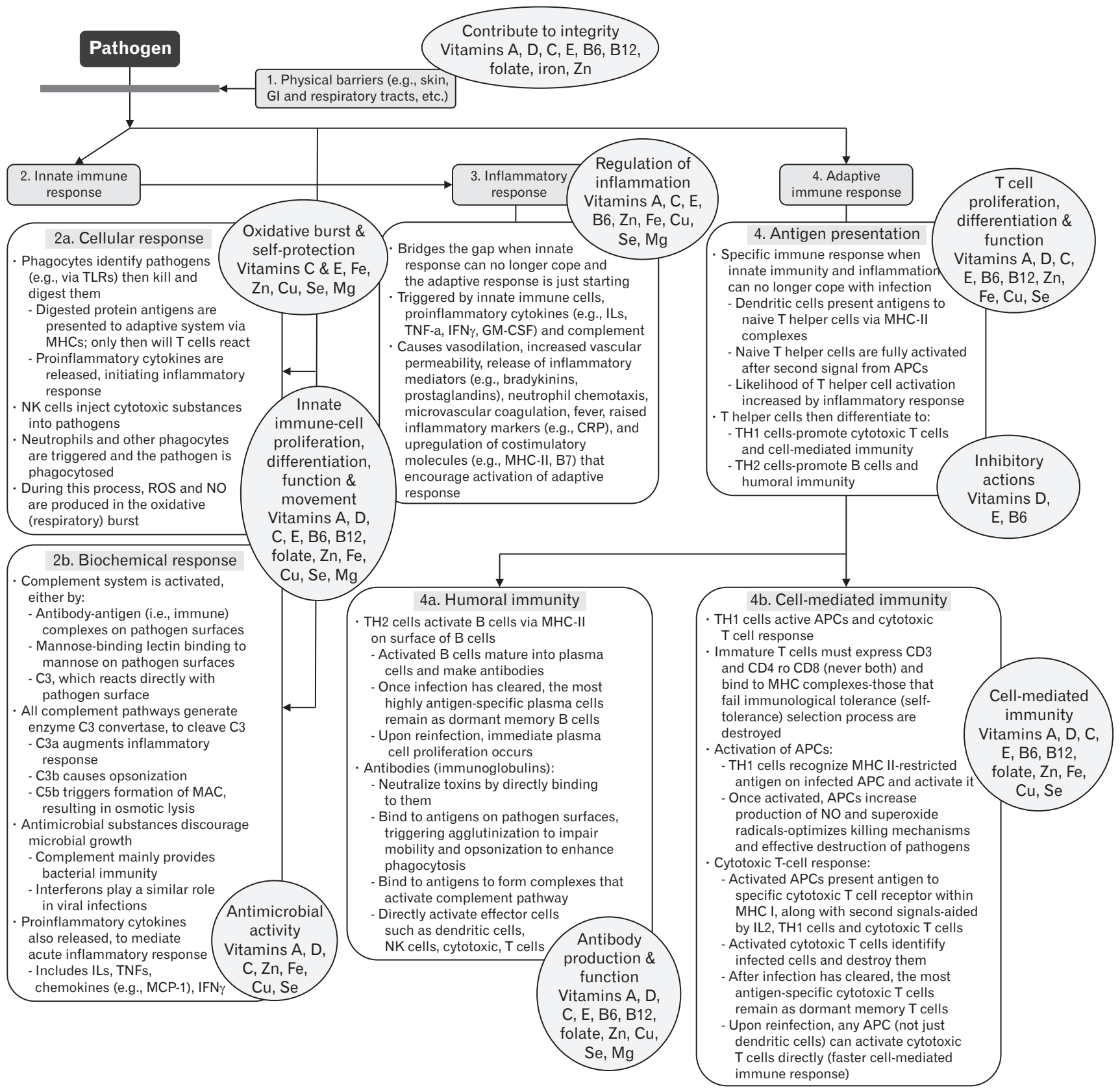

Figure 2. Protection from pathogens with nutritional components that contribute to immune cell regulation. This schema illustrates the important bioactive components of immune systems and pathogen entry. These components are often vitamins and minerals that have many effects; (1) Vitamins A, D, C, E, B6, and B12; folate, Fe, and Zn contribute to protecting the body (via the skin, gastrointestinal [Gl] tract, and respiratory tract) from pathogen entry. (2a) Vitamins $\mathrm{C}$ and E, Fe, Cu, Zn, Se, and Mg contribute to oxidative bursts and self-protection in the cellular response (via major histocompatibility complexes [MHCs], toll-like receptors [TLRs], natural killer [NK] cells, neutrophils, phagocytes, and nitric oxide [NO] release). (2b) Vitamins A, D, C, E, B6, and B12; folate, Zn, Cu, Se, and Mg contribute to innate immune cell proliferation, differentiation, function, and movement. Additionally, vitamins A, D, and C; Zn, Fe, Cu, and Se contribute antimicrobial activity in the biochemical response (via complement component 3 [C3], interferons [IFNs], monocyte chemoattractant protein-1 [MCP-1]). (3) Vitamins A, C, E, and B6; Fe, Cu, Se, and Mg help to regulate inflammation in the inflammatory immune response (via interleukins [LLs], tumor necrosis factor [TNF- $\alpha$, IFN- $\gamma$, C-reactive protein [CRP], and MHC-II). (4) Vitamins A, B6, C, D, and E; Zn, Cu, and Se contribute to T cell proliferation, differentiation, and function, while vitamins $\mathrm{B} 6, \mathrm{D}$, and $\mathrm{E}$ contribute to inhibitory actions in the adaptive immune response (via antigen-presenting cells, antigenpresenting cell [APC], T helper [TH]1, TH2, and MHC-II). (4a) Vitamins A, B6, B12, C, and D; folate, Zn, Cu, Se, and Mg contribute to antibody production and function in humoral immunity. (4b) Vitamins A, B6, B12, C, D, and E; folate, Zn, Fe, Cu, and Se contribute to cell-mediated immunity (via CD3, CD4, CD8, APC, MHC-I, IL, and TH1) ${ }^{21)}$ ROS, reactive oxygen species; GM-CSF, granulocyte-macrophage colony-stimulating factor.

sponse to antigen presentation, and virus clearance against influenza were observed. ${ }^{44)} \mathrm{Balb} / \mathrm{c}$ mice were fed an HFD for 10 weeks, followed by sensitization and exposure to house dust mite (HDM). In addition, mice were exposed to palmitic acid (PA) for 4 weeks. There were significant increases in body weight and increased lung macrophages, including circulating monocytes and alveolar macrophages. After HDM 
sensitivity and exposure, an increase in the total number of bronchoalveolar lavage fluid (BALF) cells, including neutrophils and eosinophils, was detected. Furthermore, the production of IL- $1 \beta$ and TNF- $\alpha$ with increased lipopolysaccharides in PA-induced MCP-1 and macrophages was observed. Among HDM mice treated with PA, there was an increase in the total number of BALF cells, including neutrophils, compared to that in normal mice, though not eosinophils. Thus, it can be deduced that consumption of HFD in COVID-19 delays the adaptive immune response adversely affects the host defense system and increases symptoms resulting in a damaged lung. ${ }^{72)} \mathrm{A}$ Western diet (WD), based on HFD-weighted nutrition, now accounts for the majority of dietary habits in most countries. This diet increases innate immunity; however, it significantly impairs adaptive immunity, causes chronic inflammation, and seriously impairs host defense against viral pathogens such as SARS-COV-2. ${ }^{71)}$

\section{OTHER VIRAL DISEASES AND COVID-19: THE LINK BETWEEN NUTRITIONAL SUPPORTS}

The pathogenesis of COVID-19 is known to affect the respiratory system in most patients. ${ }^{73)}$ However, SARS-COV-2 infection causes other symptoms, such as fever, fatigue, cytokine increase, viral sepsis initiation, pneumonitis, ARDS, respiratory failure, shock, organ failure, inflammatory-induced lung damage, and potential death. ${ }^{74)}$ There has not yet been a drug or supplement that provides full recovery from COVID-19. ${ }^{16,62)}$ Many trials are ongoing to address hypotheses on COVID-19 treatment, and there are important questions regarding whether certain nutrients and food patterns can prevent viral infection or decrease its severity. ${ }^{75)}$ The immune system plays a vital role in this disease, ${ }^{62)}$ and nutrition plays an important role in strengthening the immune system. Therefore, nutritional therapy is needed to strengthen the immune system and treat prevent respiratory failure in COVID-19. ${ }^{76)}$ Vitamins such as A, B6, B12, C, D, and E, as well as trace elements such as $\mathrm{Mg}$, $\mathrm{Se}, \mathrm{Fe}, \mathrm{Cu}$, and $\mathrm{Zn}$, have shown a positive effect on some viral infections, apart from the normal functioning of the immune system (Figure 2). 21,42,57,62,63)

Nutritional status is an important factor in the development of infectious diseases; it is assumed that it may affect the final results of patients with COVID-19. ${ }^{23)}$ According to the recently published European Society of Clinical Nutrition and Metabolism guidelines, enteral nutrition was preferred because it is difficult to provide nutrition for patients receiving MV in the ICU. ${ }^{77)}$ However, patients with SARS-COV-2 infection may experience gastrointestinal symptoms such as vomiting and diarrhea, making oral feeding difficult. Enteral nutrition can be considered safe, and it can also be associated with increased gastrointestinal complication risks in patients with severe hypoxemia who receive MV in prone position. ${ }^{78)}$ In patients with ARDS/acute lung injury, it has been demonstrated that enteral diets containing eicosapentaenoic acid, gamma-linolenic acid, and antioxidant agents can provide clinical benefits on days of oxygenation and ventilation, and modulation of the inflammatory response with specific lipid emulsions may be beneficial. ${ }^{77,79)}$ However, whether pneumonia associated with COVID-19 responds to these treatments and specific enteral diets and supplements should be researched. ${ }^{79}$

\section{Vitamin A}

According to the data obtained from 15 randomized studies to examine the relationship of vitamin A supplement with mortality and clinical symptoms of pneumonia in children, vitamin A supplementation did not decrease the mortality rate of the disease $(P>0.05)$. However, clinical symptoms (reduction of fever and cough, abnormal chest $\mathrm{X}$ ray results, and shortening the length of hospital stay) gave positive results $(\mathrm{P}<0.05)$ while not showing any side effects. For this reason, vitamin A may be a promising option for treating this new coronavirus and preventing lung infection. ${ }^{80)}$ Vitamin $\mathrm{A}$ is an antioxidant, and supplementation has been reported to play a role in reducing morbidity, mortality, and disease symptoms in different infectious diseases such as diarrheal disease, measles, acquired immunodeficiency syndrome (AIDS), measles-related pneumonia, malaria, and infectious bronchitis virus. ${ }^{81,82)}$ However, in a meta-analysis of five studies involving 2,177 children aged 1 month to 6 years with acute lower respiratory tract infection (RTI), high-dose vitamin A intake did not have a role in the normalization of fever, respiratory rate, oxygen dependence, discharge time, or mortality parameters. In other words, high vitamin A doses (100,000-200,000 IU for infants and 200,000-400,000 IU for the 1-6-year-olds) did not improve pneumonia in children. ${ }^{83)}$ This result may be related to geographical heterogeneity or the fact that vitamin A supplementation was administered to children and not adults.

\section{Vitamin B}

In an in vitro study, the application of UV light and vitamin B2 in MERS-COV infection were tested with pooled plasma $(n=3)$ and repeated with plasma units $(n=6)$. The infectious titer was reduced below the detection limit after treatment; mean log reductions in viral titers were $\geq 4.07$ and $\geq 4.42$ for collected and individual donor plasma. This study suggests that treatment with UV light and vitamin B2 may reduce the risk of MERS-COV transfusion and transmission. ${ }^{84)}$ Treatment with vitamin B3 in ventilator-induced lung injury in mouse models has been found to inhibit neutrophil infiltration into the lungs with a strong anti-inflammatory effect. However, this approach should be used with caution, as it can lead to significant hypoxemia. ${ }^{85)}$ With careful planning, B vitamins such as B3 can be selected as an immunomodulatory supplement option for COVID-19 treatment. ${ }^{21,85,86)}$

\section{Vitamin C}

Vitamin C is an antioxidant. In one study, $200 \mathrm{mg} / \mathrm{d}$ of vitamin C was administered to hospitalized elderly patients with acute respiratory infections. Improvement in respiratory symptoms was achieved in patients, and $80 \%$ fewer deaths were found in the patient groups receiving vitamin C. In three human-controlled studies, the incidence of pneumonia was significantly lower in the groups supplemented with vitamin $\mathrm{C}$. These findings show that vitamin $\mathrm{C}$ may effectively reduce 
respiratory infections. ${ }^{87)}$ In a meta-analysis of 12 controlled studies including 1,766 patients, the effect of vitamin $\mathrm{C}$ on intensive care patients was examined. Oral Vitamin C consumption $(2.0 \mathrm{~g} / \mathrm{d})$ decreased the duration of ICU stay by an average of $7.8 \%$, the ICU stay duration by $8.6 \%$, and the MV time by $18.2 \%$. These percentages indicate that vitamin C supplementation can be effective in the ICU. ${ }^{73)}$ Vitamin C is beneficial to reduce respiratory symptoms, ${ }^{73,87,88)}$ and these results may help address COVID-19. In addition, intravenous vitamin C plays an effective role in treating polio, though magnesium chloride is more effective than vitamin C in polio. ${ }^{89,90)}$ However, in a randomized, doubleblind, placebo-controlled, multicenter trial, in patients with sepsis and ARDS supplemented with vitamin $C$, no specific differences were found compared with placebo and experimental groups. According to the Sequential Organ Failure Assessment score, the score of the group that received vitamin $C$ decreased by 3 points, whereas that of the placebo group decreased by 3.5 points. Furthermore, significant results were found in parameters such as inflammation (C-reactive protein levels) and vascular injury (thrombomodulin levels), which showed only a small difference between the placebo and experimental groups. In addition, vitamin $\mathrm{C}$ does not affect parameters such as altered markers of inflammation or organ dysfunction score improvement, vascular injury, or sepsis in ARDS patients. ${ }^{91)}$ More clinical studies are needed to investigate the effects of vitamin $\mathrm{C}$ on these diseases.

\section{Vitamin D, Vitamin E, and Flavonoids}

Vitamin D is an important vitamin to fight against pathogens. It is assumed to reduce the incidence and risk of death in influenza and COVID-19. The appropriate dosage and serum 25-hydroxyvitamin D (25(OH)D) concentrations were investigated. In a meta-analysis, 25 randomized controlled trials (RCTs; 11,321 participants, aged 0-95 years old) on the risk of acute respiratory infection (ARI) with vitamin D supplementation were performed. Individual patient data analysis was obtained from 10,933 participants (96.6\%). Supplementation of vitamin D was found to reduce the risk of ARI in all participants (corrected ratio rate [adjusted odds ratio], 0.88; 95\% CI, 0.81-0.96; heterogeneity $\mathrm{P}<0.001$ ), indicating that vitamin $\mathrm{D}$ can be used as a therapeutic option. ${ }^{42)}$ In another randomized controlled study, ICU patients with low plasma vitamin levels (serum 25(OH)D level $<20 \mathrm{ng} / \mathrm{mL}$ ) were given $250,000 \mathrm{IU}$ and 500,000 IU of D3 for 5 days. In the 250,000 IU and 500,000 IU vitamin D3-administered groups, there was a significant reduction in hospital stay length compared to that in the placebo group (25 \pm 14 and $18 \pm 11$ days compared to $36 \pm 19$ days, respectively; $\mathrm{P}=0.03) .{ }^{92)}$ Therefore, vitamin $\mathrm{D}$ seems to decrease the length of hospital stay. The benefits of vitamins and their combinations have been revealed in previous studies; for example, in a case study, reduced vitamin $\mathrm{D}$ and $\mathrm{E}$ levels in calves have been shown to cause bovine coronavirus infection. During 8-day of total 14-day post-inoculation, serum 25(OH)D and E vitamin concentrations in infected calves decreased by $51 \%$ and $82 \%$, respectively. Thus, an inverse relationship was observed between vitamin D and E status, and serum amyloid A suggested that the acute phase response due to infection contributed to re- ducing vitamin D and E status in these animals. ${ }^{93)}$ In a study measuring the relationship between vitamin D levels in blood and COVID-19 occurrence, 348,598 UK Biobank participants' data were used. COVID-19 cases were observed in 449 patients, and patients' vitamin D deficiency and disease status were compared and found to be meaningfully associated (OR, 0.99; 95\% CI, 0.99-0.999; $\mathrm{P}=0.013$ ); however, after adjustment for confounders, the association was found to be meaningless (OR, 1.00; 95\% CI, 0.998-1.01; $\mathrm{P}=0.208$ ). ${ }^{94)}$ This study was conducted with ethnic minority groups; therefore, it may not represent the general population. Many studies support the advantages of vitamin D; therefore, further clinical studies with vitamin D should be conducted to confirm this.

Polyphenols are a group of bioactive chemicals. Flavonoids are a subgroup of polyphenols, and the beneficial effects of these biochemicals have been revealed in in vitro studies; two flavonoids from Pterogyne nitens have been found to inhibit hepatitis $\mathrm{C}$ virus entry. Flavonoids 1 and 2 at a non-cytotoxic amount were observed to inhibit virus entry up to $45.0 \%$ and $78.7 \%$, respectively. ${ }^{95)}$ Therefore, flavonoids may also inhibit SARS-COV-2 entry; these studies need to be performed for SARS-COV-2.

\section{Minerals}

In a study conducted with low concentrations of $\mathrm{Zn}$ and pyrithione (PT) combination $(2 \mu \mathrm{M} \mathrm{Zn}[2+]$ and $2 \mu \mathrm{M}$ PT) in cell culture, Zn was found to inhibit the in vitro activity of SARS-COV and equine arteritis virus (EAV). Zn blocked the initiation step of EAV RNA synthesis; however, template binding was reduced, and RNA-dependent RNA polymerase elongation was inhibited in SARS-COV. ${ }^{96)}$ In another study, RTI was associated with $\mathrm{Zn}, \mathrm{Cu}$, and Fe trace elements. Hair levels of these elements were also investigated. Thirteen studies were evaluated, and P-values were significant for each element. The deficiency of these elements may be associated with RTI; however, more studies are needed. ${ }^{97)}$ Se plays an important role in the fight against pathogens. One $\mu \mathrm{M} \mathrm{Se} / \mathrm{L}$ of host blood is associated with immunocompetence and mutation of viruses. ${ }^{98)}$ Influenza H5N1, 2009 H1N1, AIDS, Ebola hemorrhagic fever, and SARS diseases may be associated with Se deficiency. ${ }^{99)}$ At the same time, another study reported that Se deficiency might increase the pathology of an influenza virus infection and trigger changes in the Coxsackievirus genome, which allows the virus to gain virulence due to a genetic mutation. For this reason, taking the Se trace element in the required amount can be an effective agent in the fight against pathogens. ${ }^{100)}$ Based on the conclusions drawn in these studies, trace elements have important effects on fighting infections. Se can be an effective supplement for preventing or reducing SARS-COV-2 infection. Zn supplementation acts on COVID-19-related symptoms, such as lower respiratory infection and diarrhea, and affects SARSCOV-2 itself. In recurrent lung diseases and ARIs, Fe deficiency has been reported as a risk factor. ${ }^{21,86)}$

\section{Energy Intake and Macronutrients}

Adequate and balanced nutrition is important for health. It is impor- 
tant to maintain an adequate calorie intake to avoid malnutrition. In a case study, high-calorie intensive diets, whey proteins supplementation, multivitamin intravenous infusion, and multimineral trace element solutions were provided to patients with COVID-19. Therefore, preventing malnutrition was found to play an important role in fighting the disease. ${ }^{101)}$ Attention should be paid to providing adequate protein (1.5 g/kg/d) and calorie intake (25-30 kcal/ $\mathrm{kg} / \mathrm{d})$. In a cohort study with $801 \mathrm{ICU}$ patients, $1 \mathrm{~g} / \mathrm{kg}$ daily protein delivery increase (OR, 0.83; 95\% CI, 0.74-0.94; $\mathrm{P}=0.002$ ) for 90 days changed the patients' post-discharge mortality rate from $13.9 \%$ to $17 \%$ lower (95\% CI, 6-26); this means that higher protein intake by these ICU patients decreased their odds of mortality. ${ }^{102,103)}$ Furthermore, 1.5-2.5 g protein/kg per day can benefit patients. ${ }^{104)}$ In 12 RCTs, a meta-analysis was carried out by examining omega-3 supplements for 3-4 days, 7-8 days, and longer, to examine the effect of omega-3 polyunsaturated fatty acids on ARDS patients. The $\mathrm{PaO}_{2}: \mathrm{FiO}_{2}$ ratio, an important criterion in gas exchange, improved the omega 3 uptake $(\mathrm{P}=0.04)$. In the early period, ICU residence time decreased $(\mathrm{P}=0.08)$, and MV time decreased $(\mathrm{P}=0.06)$, although there was no change in mortality rate or length of hospital stay. However, there was a decrease in mortality $(\mathrm{P}=0.02)$ and a decrease in MV time ( $\mathrm{P}=0.03)$ in the ongoing omega 3 intake. These results indicate that omega-3 supplementation will produce positive results in patients with ARDS. ${ }^{105)}$ It can also be considered a potential intervention for omega-3 disease, in conjunction with protein D1, which acts as an antiviral drug. ${ }^{21,86)}$

In an adequate and balanced diet, attention should be paid to calorie intake and consumption of macronutrients, vitamins, and minerals, which may potentially benefit patients COVID-19 due to their antiinflammatory and antioxidant properties. ${ }^{101,104)}$ Therefore, nutritional support might positively affect COVID-19 symptoms.

\section{CONCLUSION}

In this review, we summarize the impact of nutrition on the immune response and its positive effects on the clinical outcomes of infectious diseases. We found that nutrition is critical in increasing the immune response, limiting viral entry, modifying clinical symptoms, and extending patient survival against RNA viral infections. It is possible that following a diet according to its immune- and symptom-related properties could be useful in protecting against severe infections in patients with COVID-19. Insufficient intake of macro- and micronutrients may increase susceptibility to infections during the COVID-19 pandemic; $^{54,71)}$ therefore, this phenomenon should be investigated by further studies.

Lifestyle habits, such as ensuring proper nutrition, are of great importance in developing resistance against infectious diseases such as COVID-19. Unhealthy diets may cause the pre-existing condition to become more chronic in patients with severe symptoms of COVID-19. For this reason, both patients and healthy individuals should pay attention to their nutritional intake during the pandemic. To prevent or recover from COVID-19, it is recommended that patients avoid satu- rated fat and high-sugar food and consume high amounts of unsaturated fats and antioxidants to strengthen their immune systems to cope with the disease. ${ }^{71,102,106)}$ Adequate intake of energy, macronutrients, vitamins, and minerals is highly recommended. Additionally, some supplements can be advantageous for the host immune system and clinical outcomes in COVID-19. There are many controversial studies in this field, but some studies provide evidence to support the fact that supplements can be beneficial in reducing the side effects of the disease. Therefore, we suggest that in vivo and in vitro studies on macro- and micronutrients such as vitamins A, B, C, D, E, and trace elements be conducted. In our opinion, based on the results from other viral studies, intake of zinc sulfate (10-20 mg/d), vitamin A (20,000 IU/ d), vitamin C (200-2,000 mg/d), vitamin D3 (2,000 IU/d), vitamin E (15 $\mathrm{mg} / \mathrm{kg} / \mathrm{d}$ ), copper supplement (7.8 mg/d), protein (1.5-2.5 g/ $\mathrm{kg}$ ), flavonoids, omega-3, and probiotics should be studied in the context of COVID-19. In addition, avoiding dehydration, high fat and other unhealthy diets is important during the COVID-19 pandemic. Recommendations related to the macronutrients and micronutrients stated above urgently need to be studied to develop nutritional therapies against SARS-COV-2. Finally, in this review, suggestions regarding these nutrients are presented with scientific evidence. The enzymebound immunosorbent assay, cytokine assay, viral entry, viral replication, clinical symptomatic response, and other tests to measure immune cell activity have been described in animal and cell models. The results of these studies should be immediately be validated in the clinical setting. COVID-19 continues its weight and seems to continue its impact. Therefore, nutritional measures should be taken to overcome the difficulty of the disease and its effects after suffering the disease.

\section{CONFLICT OF INTEREST}

No potential conflict of interest relevant to this article was reported.

\section{ORCID}

Fatmanur Zehra Zelka: https://orcid.org/0000-0001-7791-7763

Rümeysa Rabia Kocatürk: https://orcid.org/0000-0001-6769-3057

Öznur Özge Özcan: https://orcid.org/0000-0001-8992-0556

Mesut Karahan: https://orcid.org/0000-0002-8971-678X

\section{REFERENCES}

1. Wang C, Horby PW, Hayden FG, Gao GF. A novel coronavirus outbreak of global health concern. Lancet 2020;395:470-3.

2. Bogoch II, Watts A, Thomas-Bachli A, Huber C, Kraemer MU, Khan K. Pneumonia of unknown aetiology in Wuhan, China: potential for international spread via commercial air travel. J Travel Med 2020;27: taaa008.

3. World Health Organization. Our World in Data: daily vs. cumulative confirmed deaths due to COVID-9 [Internet]. Geneva: World Health Organization; 2022 [cited 2022 Jan 12]. Available from: https://our- 
worldindata.org/grapher/cumulative-covid-deaths-region.

4. World Health Organization. 2019-NCoV outbreak is an emergency of international concern [Internet]. Geneva: World Health Organization; 2020 [cited 2020 May 5]. Available from: http://www.euro.who. int/en/health-topics/health-emergencies/international-health-regulations/news/news/2020/2/2019-ncov-outbreak-is-an-emergencyof-international-concern.

5. Wang D, Hu B, Hu C, Zhu F, Liu X, Zhang J, et al. Clinical characteristics of 138 hospitalized patients with 2019 novel coronavirus-infected pneumonia in Wuhan, China. JAMA 2020;323:1061-9.

6. Li Q, Guan X, Wu P, Wang X, Zhou L, Tong Y, et al. Early transmission dynamics in Wuhan, China, of novel coronavirus-infected pneumonia. N Engl J Med 2020;382:1199-207.

7. Gralinski LE, Menachery VD. Return of the coronavirus: 2019-nCoV. Viruses 2020;12:135.

8. Banerjee A, Kulcsar K, Misra V, Frieman M, Mossman K. Bats and coronaviruses. Viruses 2019;11:41.

9. Wang JT, Sheng WH, Fang CT, Chen YC, Wang JL, Yu CJ, et al. Clinical manifestations, laboratory findings, and treatment outcomes of SARS patients. Emerg Infect Dis 2004;10:818-24.

10. Yang Y, Lu Q, Liu M, Wang Y, Zhang A, Jalali N, et al. Epidemiological and clinical features of the 2019 novel coronavirus outbreak in China. Medrxiv [Preprint] 2020 Jan 1 [Epub]. https://doi.org/10.1101/2020.0 2.10.20021675.

11. Yi Y, Lagniton PN, Ye S, Li E, Xu RH. COVID-19: what has been learned and to be learned about the novel coronavirus disease. Int J Biol Sci 2020;16:1753-66.

12. Centers for Disease Control and Prevention. Take 3 actions to fight flu [Internet]. Atlanta (GA): Centers for Disease Control and Prevention; 2020 [cited 2020 Mar 2]. Available from: https://www.cdc.gov/flu/ prevent/preventing.htm.

13. World Health Organization. Rational use of personal protective equipment for coronavirus disease (COVID-19) and considerations during severe shortages: interim guidance [Internet]. Geneva: World Health Organization; 2020 [cited 2020 Mar 2]. Available from: https:// www.who.int/publications-detail/rational-use-of-personal-protective-equipment-for-coronavirus-disease-(covid-19)-and-considerations-during-severe-shortages.

14. Grifoni A, Sidney J, Zhang Y, Scheuermann RH, Peters B, Sette A. A sequence homology and bioinformatic approach can predict candidate targets for immune responses to SARS-CoV-2. Cell Host Microbe 2020;27:671-80.

15. Tai W, He L, Zhang X, Pu J, Voronin D, Jiang S, et al. Characterization of the receptor-binding domain (RBD) of 2019 novel coronavirus: implication for development of RBD protein as a viral attachment inhibitor and vaccine. Cell Mol Immunol 2020;17:613-20.

16. Jamkhande A, Khairnar MR, Gavali N, Patil Y, Kapare SS, Bhosale KP. A review of approved COVID-19 vaccines. Rocz Panstw Zakl Hig 2021;72:245-52.

17. Calder PC, Carr AC, Gombart AF, Eggersdorfer M. Optimal nutritional status for a well-functioning immune system is an important factor to protect against viral infections. Nutrients 2020;12:1181.

18. Valdes-Ramos R, Martinez-Carrillo BE, Aranda-Gonzalez II, Guadarrama AL, Pardo-Morales RV, Tlatempa P, et al. Diet, exercise and gut mucosal immunity. Proc Nutr Soc 2010;69:644-50.
19. Wypych TP, Marsland BJ, Ubags ND. The impact of diet on immunity and respiratory diseases. Ann Am Thorac Soc 2017;14(Supplement_5):S339-47.

20. Gleeson M, Nieman DC, Pedersen BK. Exercise, nutrition and immune function. J Sports Sci 2004;22:115-25.

21. Gombart AF, Pierre A, Maggini S. A review of micronutrients and the immune system-working in harmony to reduce the risk of infection. Nutrients 2020;12:236.

22. de Faria Coelho-Ravagnani C, Corgosinho FC, Sanches FFZ, Prado CMM, Laviano A, Mota JF. Dietary recommendations during the COVID-19 pandemic. Nutr Rev 2021;79:382-93.

23. Chinese Centre for Disease Control and Prevention. Diagnosis and treatment: COVID-19 prevention and control (version 7) [Internet]. Beijing: Chinese Centre for Disease Control and Prevention; 2020 [cited 2020 Mar 3]. Available from: http://www.chinadaily.com.cn/ specials/diagnosisandtreatment-Africa.pdf.

24. Surendran SP, Moon MJ, Park R, Jeong YY. Bioactive nanoparticles for cancer immunotherapy. Int J Mol Sci 2018;19:3877.

25. Huang C, Wang Y, Li X, Ren L, Zhao J, Hu Y, et al. Clinical features of patients infected with 2019 novel coronavirus in Wuhan, China. Lancet 2020;395:497-506.

26. Xu Z, Shi L, Wang Y, Zhang J, Huang L, Zhang C, et al. Pathological findings of COVID-19 associated with acute respiratory distress syndrome. Lancet Respir Med 2020;8:420-2.

27. Qin C, Zhou L, Hu Z, Zhang S, Yang S, Tao Y, et al. Dysregulation of immune response in patients with coronavirus 2019 (COVID-19) in Wuhan, China. Clin Infect Dis 2020;71:762-8.

28. Tan M, Liu Y, Zhou R, Deng X, Li F, Liang K, et al. Immunopathological characteristics of coronavirus disease 2019 cases in Guangzhou, China. Immunology 2020;160:261-8.

29. Zhang B, Zhou X, Zhu C, Song Y, Feng F, Qiu Y, et al. Immune phenotyping based on the neutrophil-to-lymphocyte ratio and IgG level predicts disease severity and outcome for patients with COVID-19. Front Mol Biosci 2020;7:157.

30. Zhu N, Zhang D, Wang W, Li X, Yang B, Song J, et al. A novel coronavirus from patients with pneumonia in China, 2019. N Engl J Med 2020;382:727-33.

31. Chen X, Ling J, Mo P, Zhang Y, Jiang Q, Ma Z, et al. Restoration of leukomonocyte counts is associated with viral clearance in COVID-19 hospitalized patients. MedRxiv [Preprint] 2020 Jan 1 [Epub]. https:// doi.org/10.1101/2020.03.03.20030437.

32. Zheng M, Gao Y, Wang G, Song G, Liu S, Sun D, et al. Functional exhaustion of antiviral lymphocytes in COVID-19 patients. Cell Mol Immunol 2020;17:533-5.

33. TaStan C, Yurtsever B, Sir KarakuS G, Dilek KanCaGi D, Demir S, Abanuz S, et al. SARS-CoV-2 isolation and propagation from Turkish COVID-19 patients. Turk J Biol 2020;44:192-202.

34. Zhao J, Yuan Q, Wang H, Liu W, Liao X, Su Y, et al. Antibody responses to SARS-CoV-2 in patients with novel coronavirus disease 2019. Clin Infect Dis 2020;71:2027-34.

35. Cameron MJ, Bermejo-Martin JF, Danesh A, Muller MP, Kelvin DJ. Human immunopathogenesis of severe acute respiratory syndrome (SARS). Virus Res 2008;133:13-9.

36. Williams AE, Chambers RC. The mercurial nature of neutrophils: still an enigma in ARDS? Am J Physiol Lung Cell Mol Physiol 2014;306: 
L217-30

37. Channappanavar R, Perlman S. Pathogenic human coronavirus infections: causes and consequences of cytokine storm and immunopathology. Semin Immunopathol 2017;39:529-39.

38. Min CK, Cheon S, Ha NY, Sohn KM, Kim Y, Aigerim A, et al. Comparative and kinetic analysis of viral shedding and immunological responses in MERS patients representing a broad spectrum of disease severity. Sci Rep 2016;6:25359.

39. Cao X. COVID-19: immunopathology and its implications for therapy. Nat Rev Immunol 2020;20:269-70.

40. World Health Organization Regional Office for the Eastern Mediterranean. Nutrition advice for adults during the COVID-19 outbreak [Internet]. Cairo: World Health Organization Regional Office for the Eastern Mediterranean; 2020 [cited 2020 Mar 5]. Available from: http://www.emro.who.int/nutrition/nutrition-infocus/nutrition-advice-for-adults-during-the-covid-19-outbreak.html.

41. Nieman DC, Mitmesser SH. Potential impact of nutrition on immune system recovery from heavy exertion: a metabolomics perspective. Nutrients 2017;9:513.

42. Martineau AR, Jolliffe DA, Greenberg L, Aloia JF, Bergman P, DubnovRaz G, et al. Vitamin D supplementation to prevent acute respiratory infections: individual participant data meta-analysis. Health Technol Assess 2019;23:1-44.

43. Cury-Boaventura MF, Levada-Pires AC, Folador A, Gorjao R, AlbaLoureiro TC, Hirabara SM, et al. Effects of exercise on leukocyte death: prevention by hydrolyzed whey protein enriched with glutamine dipeptide. Eur J Appl Physiol 2008;103:289-94.

44. Green WD, Beck MA. Obesity impairs the adaptive immune response to influenza virus. Ann Am Thorac Soc 2017;14(Supplement_5): S406-9.

45. Rogero MM, Calder PC. Obesity, inflammation, toll-like receptor 4 and fatty acids. Nutrients 2018;10:432.

46. Calder PC. Omega-3 polyunsaturated fatty acids and inflammatory processes: nutrition or pharmacology? Br J Clin Pharmacol 2013;75: 645-62.

47. Gleeson M, Bishop NC. Special feature for the Olympics: effects of exercise on the immune system: modification of immune responses to exercise by carbohydrate, glutamine and anti-oxidant supplements. Immunol Cell Biol 2000;78:554-61.

48. Pai UA, Chandrasekhar P, Carvalho RS, Kumar S. The role of nutrition in immunity in infants and toddlers: an expert panel opinion. Clin Epidemiol Glob Health 2018;6:155-9.

49. Frei R, Akdis M, O'Mahony L. Prebiotics, probiotics, synbiotics, and the immune system: experimental data and clinical evidence. Curr Opin Gastroenterol 2015;31:153-8.

50. Sikalidis AK. Amino acids and immune response: a role for cysteine, glutamine, phenylalanine, tryptophan and arginine in T-cell function and cancer? Pathol Oncol Res 2015;21:9-17.

51. Cruzat VF, Krause M, Newsholme P. Amino acid supplementation and impact on immune function in the context of exercise. J Int Soc Sports Nutr 2014;11:61.

52. Haryanto B, Suksmasari T, Wintergerst E, Maggini S. Multivitamin supplementation supports immune function and ameliorates conditions triggered by reduced air quality. Vitam Miner 2015;4:1000128.

53. Micronutrient Information Center. Immunity in depth [Internet].
Corvallis (OR): Oregon State University, Linus Pauling Institute; 2010 [cited 2020 Mar 5]. Available from: https://lpi.oregonstate.edu/mic/ health-disease/immunity.

54. Saeed F, Nadeem M, Ahmed RS, Tahir Nadeem M, Arshad MS, Ullah A. Studying the impact of nutritional immunology underlying the modulation of immune responses by nutritional compounds: a review. Food Agric Immunol 2016;27:205-29.

55. Meydani SN, Ribaya-Mercado JD, Russell RM, Sahyoun N, Morrow FD, Gershoff SN. Vitamin B-6 deficiency impairs interleukin 2 production and lymphocyte proliferation in elderly adults. Am J Clin Nutr 1991;53:1275-80.

56. Wintergerst ES, Maggini S, Hornig DH. Immune-enhancing role of vitamin $\mathrm{C}$ and zinc and effect on clinical conditions. Ann Nutr Metab 2006;50:85-94

57. Carr AC, Maggini S. Vitamin C and immune function. Nutrients 2017;9:1211

58. Ahmed M, Henson DA, Sanderson MC, Nieman DC, Gillitt ND, Lila MA. The protective effects of a polyphenol-enriched protein powder on exercise-induced susceptibility to virus infection. Phytother Res 2014;28:1829-36.

59. Kim YS, Sayers TJ, Colburn NH, Milner JA, Young HA. Impact of dietary components on NK and Treg cell function for cancer prevention. Mol Carcinog 2015;54:669-78.

60. Maggini S, Pierre A, Calder PC. Immune function and micronutrient requirements change over the life course. Nutrients 2018;10:1531.

61. Maggini S, Wintergerst ES, Beveridge S, Hornig DH. Selected vitamins and trace elements support immune function by strengthening epithelial barriers and cellular and humoral immune responses. $\mathrm{Br} \mathrm{J}$ Nutr 2007;98 Suppl 1:S29-35.

62. Wintergerst ES, Maggini S, Hornig DH. Contribution of selected vitamins and trace elements to immune function. Ann Nutr Metab 2007;51:301-23

63. Patel N, Penkert RR, Jones BG, Sealy RE, Surman SL, Sun Y, et al. Baseline serum vitamin $A$ and $D$ levels determine benefit of oral vitamin A\&D supplements to humoral immune responses following pediatric influenza vaccination. Viruses 2019;11:907.

64. Goncalves-Mendes N, Talvas J, Duale C, Guttmann A, Corbin V, Marceau G, et al. Impact of vitamin D supplementation on influenza vaccine response and immune functions in deficient elderly persons: a randomized placebo-controlled trial. Front Immunol 2019;10:65.

65. Abu-Mouch S, Fireman Z, Jarchovsky J, Zeina AR, Assy N. Vitamin D supplementation improves sustained virologic response in chronic hepatitis C (genotype 1)-naive patients. World J Gastroenterol 2011;17:5184-90.

66. Nimer A, Mouch A. Vitamin D improves viral response in hepatitis C genotype 2-3 naive patients. World J Gastroenterol 2012;18:800-5.

67. Fiorino S, Bacchi-Reggiani ML, Leandri P, Loggi E, Andreone P. Vita$\min \mathrm{E}$ for the treatment of children with hepatitis B e antigen-positive chronic hepatitis: a systematic review and meta-analysis. World J Hepatol 2017;9:333-42.

68. Kim Y, Kim H, Bae S, Choi J, Lim SY, Lee N, et al. Vitamin C is an essential factor on the anti-viral immune responses through the production of interferon $-\alpha / \beta$ at the initial stage of influenza A virus (H3N2) infection. Immune Netw 2013;13:70-4.

69. Acevedo-Murillo JA, Garcia Leon ML, Firo-Reyes V, Santiago-Cordo- 
va JL, Gonzalez-Rodriguez AP, Wong-Chew RM. Zinc supplementation promotes a Thl response and improves clinical symptoms in fewer hours in children with pneumonia younger than 5 years old: a randomized controlled clinical trial. Front Pediatr 2019;7:431.

70. Turnlund JR, Jacob RA, Keen CL, Strain JJ, Kelley DS, Domek JM, et al. Long-term high copper intake: effects on indexes of copper status, antioxidant status, and immune function in young men. Am J Clin Nutr 2004;79:1037-44.

71. Butler MJ, Barrientos RM. The impact of nutrition on COVID-19 susceptibility and long-term consequences. Brain Behav Immun 2020;87:53-4.

72. Tashiro H, Takahashi K, Sadamatsu H, Kato G, Kurata K, Kimura S, et al. Saturated fatty acid increases lung macrophages and augments house dust mite-induced airway inflammation in mice fed with highfat diet. Inflammation 2017;40:1072-86.

73. Hemila H, Chalker E. Vitamin C can shorten the length of stay in the ICU: a meta-analysis. Nutrients 2019;11:708.

74. Prompetchara E, Ketloy C, Palaga T. Immune responses in COVID-19 and potential vaccines: lessons learned from SARS and MERS epidemic. Asian Pac J Allergy Immunol 2020;38:1-9.

75. Kalantar-Zadeh K, Moore LW. Impact of nutrition and diet on COVID-19 infection and implications for kidney health and kidney disease management. J Ren Nutr 2020;30:179-81.

76. Berthon BS, Wood LG. Nutrition and respiratory health: feature review. Nutrients 2015;7:1618-43.

77. Singer P, Blaser AR, Berger MM, Alhazzani W, Calder PC, Casaer MP, et al. ESPEN guideline on clinical nutrition in the intensive care unit. Clin Nutr 2019;38:48-79.

78. Saez de la Fuente I, Saez de la Fuente J, Quintana Estelles MD, Garcia Gigorro R, Terceros Almanza LJ, Sanchez Izquierdo JA, et al. Enteral nutrition in patients receiving mechanical ventilation in a prone position. JPEN J Parenter Enteral Nutr 2016;40:250-5.

79. Barazzoni R, Bischoff SC, Breda J, Wickramasinghe K, Krznaric Z, Nitzan D, et al. ESPEN expert statements and practical guidance for nutritional management of individuals with SARS-CoV-2 infection. Clin Nutr 2020;39:1631-8.

80. Hu N, Li QB, Zou SY. Effect of vitamin A as an adjuvant therapy for pneumonia in children: a meta analysis. Zhongguo Dang Dai Er Ke Za Zhi 2018;20:146-53.

81. Semba RD. Vitamin A and immunity to viral, bacterial and protozoan infections. Proc Nutr Soc 1999;58:719-27.

82. West CE, Sijtsma SR, Kouwenhoven B, Rombout JH, van der Zijpp AJ. Epithelia-damaging virus infections affect vitamin A status in chickens. J Nutr 1992;122:333-9.

83. Brown N, Roberts C. Vitamin A for acute respiratory infection in developing countries: a meta-analysis. Acta Paediatr 2004;93:1437-42.

84. Keil SD, Bowen R, Marschner S. Inactivation of Middle East respiratory syndrome coronavirus (MERS-CoV) in plasma products using a riboflavin-based and ultraviolet light-based photochemical treatment. Transfusion 2016;56:2948-52.

85. Jones HD, Yoo J, Crother TR, Kyme P, Ben-Shlomo A, Khalafi R, et al. Correction: Nicotinamide exacerbates hypoxemia in ventilator-induced lung injury independent of neutrophil infiltration. PLoS One 2015;10:e0128735.

86. Zhang L, Liu Y. Potential interventions for novel coronavirus in Chi- na: a systematic review. J Med Virol 2020;92:479-90.

87. Hunt C, Chakravorty NK, Annan G, Habibzadeh N, Schorah CJ. The clinical effects of vitamin C supplementation in elderly hospitalised patients with acute respiratory infections. Int J Vitam Nutr Res 1994;64:212-9.

88. Hemila H. Vitamin C intake and susceptibility to pneumonia. Pediatr Infect Dis J 1997;16:836-7.

89. Levy TE. Magnesium: reversing disease. Henderson (NV): MedFox Publishing; 2019.

90. Dean C. The magnesium miracle. 2nd ed. New York (NY): Ballantine Books; 2017.

91. Fowler AA 3rd, Truwit JD, Hite RD, Morris PE, DeWilde C, Priday A, et al. Effect of vitamin $\mathrm{C}$ infusion on organ failure and biomarkers of inflammation and vascular injury in patients with sepsis and severe acute respiratory failure: the CITRIS-ALI randomized clinical trial. JAMA 2019;322:1261-70.

92. Han JE, Jones JL, Tangpricha V, Brown MA, Brown LA, Hao L, et al. High dose vitamin D administration in ventilated intensive care unit patients: a pilot double blind randomized controlled trial. J Clin Transl Endocrinol 2016;4:59-65.

93. Nonnecke BJ, McGill JL, Ridpath JF, Sacco RE, Lippolis JD, Reinhardt TA. Acute phase response elicited by experimental bovine diarrhea virus (BVDV) infection is associated with decreased vitamin $\mathrm{D}$ and $\mathrm{E}$ status of vitamin-replete preruminant calves. J Dairy Sci 2014;97: 5566-79.

94. Hastie CE, Mackay DF, Ho F, Celis-Morales CA, Katikireddi SV, Niedzwiedz CL, et al. Vitamin D concentrations and COVID-19 infection in UK Biobank. Diabetes Metab Syndr 2020;14:561-5.

95. Shimizu JF, Lima CS, Pereira CM, Bittar C, Batista MN, Nazare AC, et al. Flavonoids from Pterogyne nitens inhibit hepatitis $\mathrm{C}$ virus entry. Sci Rep 2017;7:16127.

96. te Velthuis AJ, van den Worm SH, Sims AC, Baric RS, Snijder EJ, van Hemert MJ. $\mathrm{Zn}(2+)$ inhibits coronavirus and arterivirus RNA polymerase activity in vitro and zinc ionophores block the replication of these viruses in cell culture. PLoS Pathog 2010;6:e1001176.

97. Mao S, Zhang A, Huang S. Meta-analysis of Zn, Cu and Fe in the hair of Chinese children with recurrent respiratory tract infection. Scand J Clin Lab Invest 2014;74:561-7.

98. Broome CS, McArdle F, Kyle JA, Andrews F, Lowe NM, Hart CA, et al. An increase in selenium intake improves immune function and poliovirus handling in adults with marginal selenium status. Am J Clin Nutr 2004;80:154-62.

99. Harthill M. Review: micronutrient selenium deficiency influences evolution of some viral infectious diseases. Biol Trace Elem Res 2011;143:1325-36

100. Beck MA, Shi Q, Morris VC, Levander OA. Rapid genomic evolution of a non-virulent coxsackievirus B3 in selenium-deficient mice results in selection of identical virulent isolates. Nat Med 1995;1:433-6.

101. Caccialanza R, Laviano A, Lobascio F, Montagna E, Bruno R, Ludovisi $S$, et al. Early nutritional supplementation in non-critically ill patients hospitalized for the 2019 novel coronavirus disease (COVID-19): rationale and feasibility of a shared pragmatic protocol. Nutrition 2020;74:110835.

102. Brugliera L, Spina A, Castellazzi P, Cimino P, Arcuri P, Negro A, et al. Nutritional management of COVID-19 patients in a rehabilitation 
unit. Eur J Clin Nutr 2020;74:860-3.

103. Weijs PJM, Mogensen KM, Rawn JD, Christopher KB. Protein intake, nutritional status and outcomes in ICU survivors: a single center cohort study. J Clin Med 2019;8:43.

104. Hoffer LJ, Bistrian BR. What is the best nutritional support for critically ill patients? Hepatobiliary Surg Nutr 2014;3:172-4.

105. Langlois PL, D’Aragon F, Hardy G, Manzanares W. Omega-3 polyun- saturated fatty acids in critically ill patients with acute respiratory distress syndrome: a systematic review and meta-analysis. Nutrition 2019;61:84-92.

106. Connaughton RM, McMorrow AM, McGillicuddy FC, Lithander FE, Roche HM. Impact of anti-inflammatory nutrients on obesity-associated metabolic-inflammation from childhood through to adulthood. Proc Nutr Soc 2016;75:115-24. 